\title{
INVESTIGATION OF AVERAGE DAILY WATER CONSUMPTIONAND ITS IMPACT ON WEIGHT GAIN IN CAPTIVE COMMON BUZZARDS (BUTEO BUTEO)
}

\author{
C. P. Okoli ${ }^{1}$, J. O. Aiyedun ${ }^{2}$ and O. O. Oludairo ${ }^{2 *}$ \\ ${ }^{1}$ Department of Veterinary Medicine and Surgery, Faculty of Veterinary Medicine, University of Abuja, Abuja, \\ Nigeria; ${ }^{2}$ Department of Veterinary Public Health and Preventive Medicine, Faculty of Veterinary Medicine, \\ University of Ilorin, Nigeria
}

\begin{abstract}
This investigation was to find out whether captive common buzzards need additional drinking water to complement the water they obtain from their pre-slaughtered meat meals and to investigate their average daily water requirements. Twenty five (25) common buzzards were studied at the wildlife hospital and rehabilitation centre Aegina, Greece with weight ranging between $498.4 \mathrm{~g}$ and $911 \mathrm{~g}$. Large quantity of potable water was measured equally into same size ceramic bowls and served each bird under study in separate individual paper boxes. At the end of 24 hours, the left over water was carefully brought out and re-measured to determine the quantity the birds have consumed. A control was set with a ceramic bowl with same quantity of water put in a paper box without a bird to determine the quantity of water lost to the atmosphere through evaporation on each day of the experiment. The water lost from the control on a daily basis was corrected in order to determine the quantity the common buzzards consumed daily. The weight of the studied buzzards were carefully taken and recorded 6 times each during the study period with $\mathrm{W}_{1}$ and $\mathrm{W}_{6}$ as entry and exit weights respectively. The mean of $\mathrm{W}_{1}-\mathrm{W}_{6}$ was used for the computation of the average percentage live body weight of the buzzards. The investigation revealed that captive common buzzards took water every day and the average daily water consumption of $724.9 \mathrm{~g}$ buzzard was $31.4 \mathrm{cc}$ or $4.3 \%$ of its live body weight. The investigation further shows that the average water lost by evaporation daily $(10.7 \mathrm{cc})$ and that consumed by each buzzard daily $(31.4 \mathrm{cc}$ ) add up to $5.8 \%$, equivalent of the average live body weight of the studied captive common buzzards which was $724.9 \mathrm{~g}$. The regression coefficient indicated that wt.gain / loss $=0.942+1.795 \mathrm{H}_{2} \mathrm{O}$. This implies that a unit increase in the average quantity of water consumed resulted in a corresponding increase of 1.795 body weight gain by the captive common buzzards.
\end{abstract}

Keywords: Daily water consumption, weight gain, captive common buzzards

\section{INTRODUCTION}

Water is essential for life and needed for maintenance of homeostasis, intracellular and extra cellular fluids, digestion and absorption, transportation of nutrients, elimination of wastes, haemopoiesis, thermoregulation, production of hormones and enzymes. Water is a universal solvent for countless elements, organic and inorganic compounds, chemicals and contaminants (Patrick, 1993; Wobeser, 2002; Paul, 2003).

According to a publication by Penn state extension in September 2013, many birds will eat snow in order to get sufficient water in the winter. When their normal water sources are frozen, only raptors get their moisture from their live prey. Furthermore, consuming water is more important than food in animals (Anon, 2015).

Common buzzards in the wild are known to feed on a variety of food ranging from small rodents to small mammals, birds, reptiles, amphibians, large insects and worms (Bird and Ho, 1976; Amadon and Bull, 1988; Arroyo et al., 2004). This implies that they take their animal preys whole with the entire viscera and the water there in. Since common buzzards are commonly seen in open country, it is possible that they also drink water from brooks, streams, run-off water from rains and left over from human activities (Cooper, 1988; Burrow and Demey, 2001; Paul, 2003).

In captivity, common buzzards are fed with dressed, frozen pre-slaughtered chicken and beef (Patrick, 1993). It is therefore necessary to find out how common buzzards would make up for the short fall in water following captivity, confinement and feeding of food other than what they take in the wild. The determination of the average quantity of water consumed by captive common buzzards per day is a logistic tool for conservationists, teachers of wildlife medicine, researchers, ornithologists and wildlife veterinarians (Aguirre, 2009).

*Corresponding e-mail address: oludairo@ hotmail.com 


\section{P. Okoli and others}

\section{MATERIALS AND METHODS}

Twenty five (25) buzzards were randomly picked from those that were brought into the Hellenic wildlife hospital and rehabilitation center Aegina, Greece between January and December, 2009. The birds underwent treatment and good care whilst the investigation lasted. Treatments were administered by the researcher assisted by other staff of the center. At the beginning each common buzzard for study was carefully wrapped with clean cotton cloth and placed on electronic weighing scale to obtain its weight. After reading and recording the weight, the birds were carefully put into perforated paper boxes whose floor was lined with strips of paper. The paper boxes were kept on top of wooden pallets and each paper box had only one buzzard put in it for the study.

Potable water was measured with sterile syringes and put into clean ceramic bowls of equal capacity and dimension. The birds were served the same quantity of water every day. Their weights were taken and recorded every 4 hours, 6 times daily throughout the period of the study. The relative quantity of water consumed by each bird per day was obtained by deducting the quantity of water left in the ceramic bowls from what was served 24 hours earlier (Aguirre, 2009).

In order to correct the water lost due to the atmosphere through evaporation the same quantity of water served each bird each day was put in a clean ceramic bowl of the same dimension and put into a paper box in the same room without a common buzzard to serve as a control. The quantity of water left in the control bowl was measured with syringe the next day and subtracted from what was served a day before to obtain the quantity of water lost to the atmosphere through evaporation. The statistical analysis was done using ANOVA.

\section{RESULTS AND DISCUSSION}

Weights $\left(\mathrm{W}_{1}-\mathrm{W}_{6}\right)$ of the Studied Common Buzzards $\left(\mathrm{B}_{1}-\mathrm{B}_{25}\right)$ taken at Regular Intervals, their Average Weight $(\mathrm{g})$, and their average daily water consumption (cc) as shown in table 1 indicates that three common buzzards, $\mathrm{B}_{1}, \mathrm{~B}_{5}, \mathrm{~B}_{11}$ lost weight while the other twenty two gained weight.

Table 1. Interval weight, average weight gain/loss, daily water consumption

\begin{tabular}{llllllllll}
\hline Buzzard & $\mathrm{W}_{1}(\mathrm{~g})$ & $\mathrm{W}_{2}(\mathrm{~g})$ & $\mathrm{W}_{3}(\mathrm{~g})$ & $\mathrm{W}_{4}(\mathrm{~g})$ & $\mathrm{W}_{5}(\mathrm{~g})$ & $\mathrm{W}_{6}(\mathrm{~g})$ & $\begin{array}{l}\text { Average } \\
\text { weight }(\mathrm{g})\end{array}$ & $\begin{array}{l}\text { Wt. gained/ } \\
\text { lost }(\mathrm{g})\end{array}$ & $\begin{array}{l}\text { Average qty } \mathrm{H}_{2 \mathrm{O}} \\
\text { Consumed/day }\end{array}$ \\
\hline $\mathrm{B}_{1}$ & 911 & 847.5 & 847.5 & 838 & 829.7 & 829.7 & 855.0 & -56 & 26.1 \\
$\mathrm{~B}_{2}$ & 845 & 839 & 867 & 858.5 & 853.5 & 853.9 & 852.8 & 7.8 & 33.9 \\
$\mathrm{~B}_{3}$ & 614.2 & 623 & 652.2 & 681.6 & 723.4 & 724.1 & 669.8 & 55.6 & 39.5 \\
$\mathrm{~B}_{4}$ & 568 & 636.9 & 721 & 689.3 & 677.2 & 678 & 661.8 & 93.8 & 33.5 \\
$\mathrm{~B}_{5}$ & 823 & 789.5 & 786 & 780.2 & 777 & 777.3 & 788.8 & -34.2 & 26.0 \\
$\mathrm{~B}_{6}$ & 567.4 & 602 & 664.5 & 679 & 705 & 705.2 & 653.9 & 86.5 & 26.0 \\
$\mathrm{~B}_{7}$ & 498.4 & 523 & 513 & 521 & 534 & 536 & 520.9 & 22.5 & 27.3 \\
$\mathrm{~B}_{8}$ & 619 & 658.1 & 705 & 708.4 & 713.4 & 713.4 & 686.2 & 67.2 & 36.2 \\
$\mathrm{~B}_{9}$ & 731 & 788.5 & 833 & 845 & 857 & 856 & 818.4 & 87.4 & 40.5 \\
$\mathrm{~B}_{10}$ & 565 & 641.2 & 663 & 671.3 & 680.1 & 679.8 & 650.1 & 85.1 & 40.5 \\
$\mathrm{~B}_{11}$ & 831 & 819.8 & 784.5 & 789.1 & 795 & 797.1 & 802.8 & -28.2 & 33.5 \\
$\mathrm{~B}_{12}$ & 568.8 & 573 & 579.1 & 578.5 & 578.1 & 582 & 576.6 & 7.8 & 30.7 \\
$\mathrm{~B}_{13}$ & 673.2 & 679 & 693.4 & 693.8 & 695 & 696.7 & 688.5 & 15.3 & 32.2 \\
$\mathrm{~B}_{14}$ & 601.5 & 619 & 630 & 635.2 & 638 & 643.7 & 627.9 & 26.4 & 33.4 \\
$\mathrm{~B}_{15}$ & 550 & 630.2 & 639 & 641.9 & 644.8 & 646 & 625.3 & 75.3 & 28.7 \\
$\mathrm{~B}_{16}$ & 669 & 720.5 & 727 & 759 & 801.2 & 803.1 & 746.6 & 77.6 & 29.0 \\
$\mathrm{~B}_{17}$ & 731.8 & 720 & 709 & 797 & 688.5 & 689 & 705.9 & 25.9 & 28.6 \\
$\mathrm{~B}_{18}$ & 767.5 & 811 & 835.5 & 843 & 850 & 852.4 & 826.6 & 59.1 & 34.7 \\
$\mathrm{~B}_{19}$ & 637.8 & 621 & 603 & 598 & 597.1 & 597.5 & 784.1 & 146.3 & 29.5 \\
$\mathrm{~B}_{20}$ & 694 & 759.1 & 803.3 & 849 & 885 & 885.9 & 812.7 & 118.7 & 34.7 \\
$\mathrm{~B}_{21}$ & 790.4 & 941.3 & 948.5 & 946 & 939 & 943 & 918 & 127.6 & 29.9 \\
$\mathrm{~B}_{22}$ & 568 & 579.5 & 603.2 & 627.5 & 647 & 646.1 & 611.9 & 43.9 & 29.7 \\
$\mathrm{~B}_{23}$ & 695.8 & 763 & 875 & 861.5 & 865.4 & 865.7 & 818.0 & 122.2 & 21.0 \\
$\mathrm{~B}_{24}$ & 598.5 & 629.8 & 658.1 & 662.7 & 667 & 668 & 647.3 & 48.8 & 25,6 \\
$\mathrm{~B}_{25}$ & 620 & 721.4 & 818 & 819.8 & 823.4 & 829.4 & 772.0 & 152.0 & 35.4 \\
Average & 669.5 & 702.5 & 725.6 & 731 & 738.6 & 740.0 & 724.9 & 57.4 & 31.4 \\
\hline & & & & & & & & & \\
\hline
\end{tabular}


Water intake in captive common buzzard

The average daily water consumed is as shown in the table, ranging between 21.0 and $40.5 \mathrm{cc}$. These were also reflected in Figures 1 and 2. The average daily water consumption for captive common buzzard is $31.4 \mathrm{cc}$.

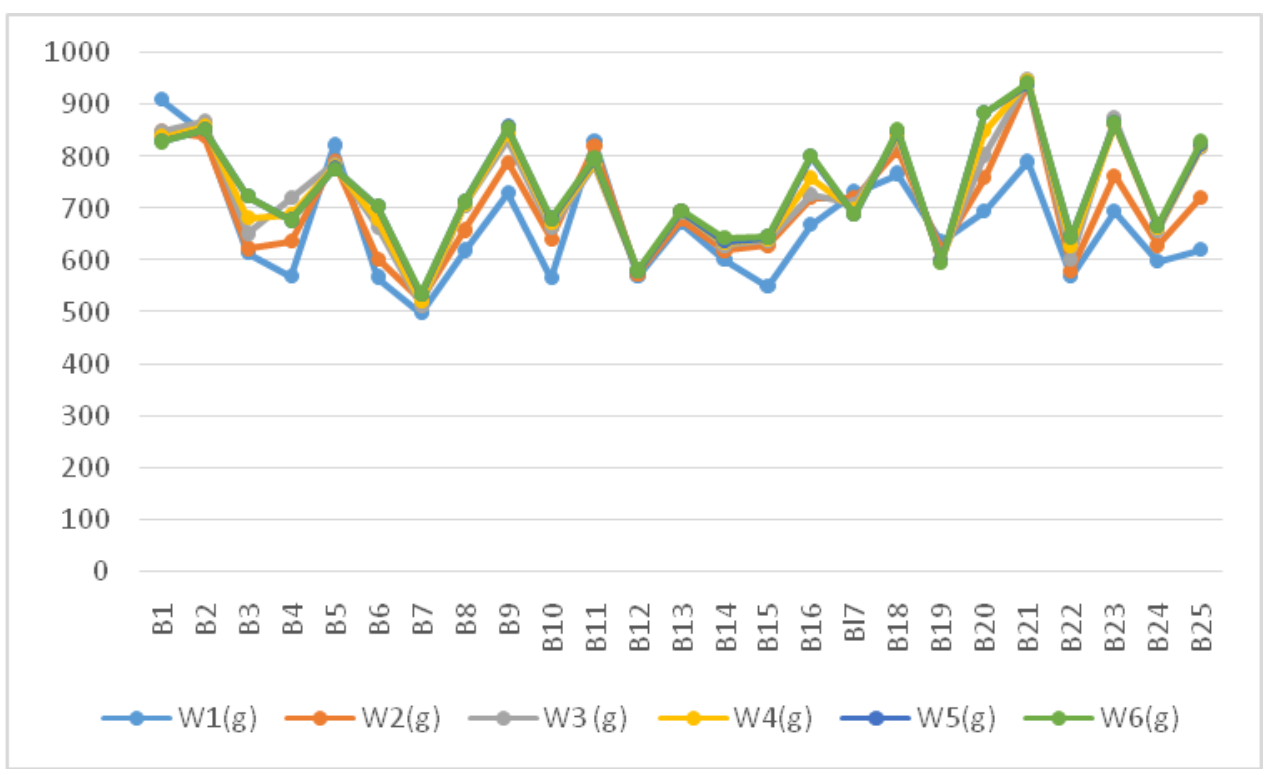

Fig. 1. Graph of common buzzard and their weekly interval weights $(\mathrm{g})$

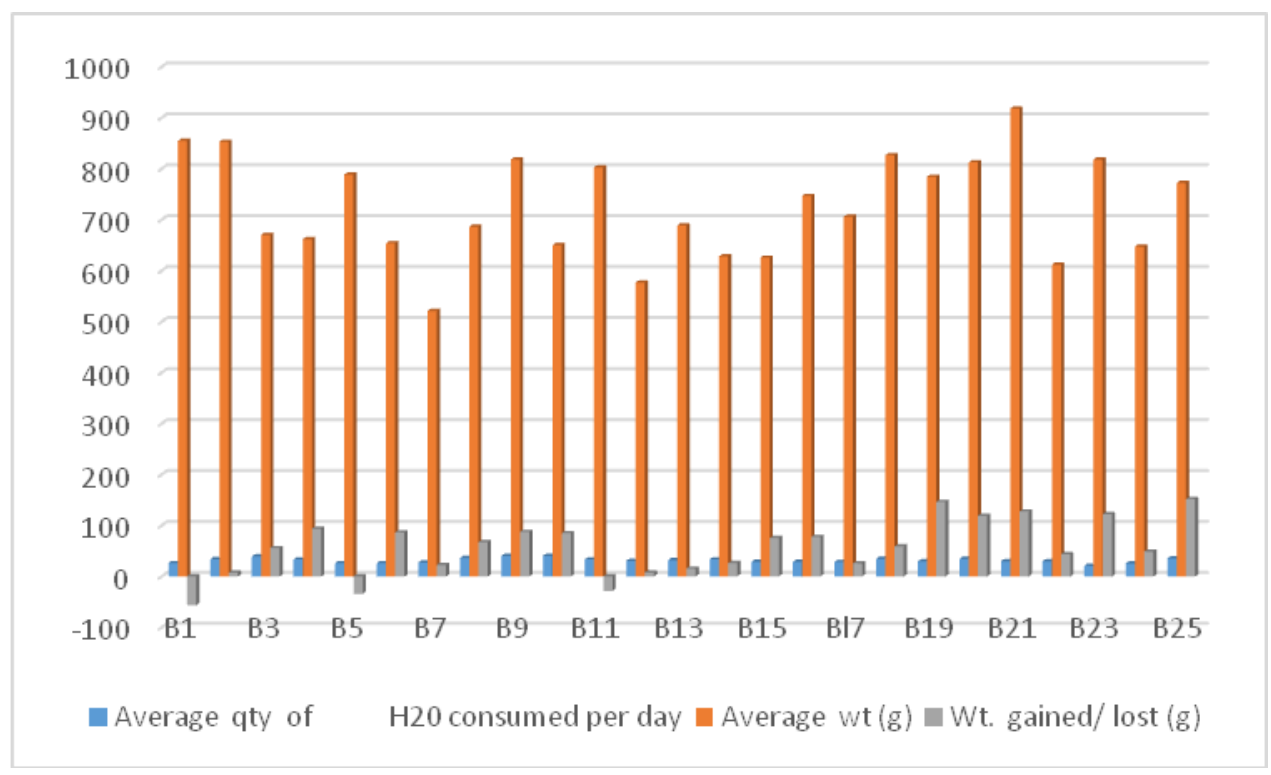

Fig. 2. Graph of average weight (g), average quantity of $\mathrm{H}_{2} \mathrm{O}$ consumed per day and weight gained/lost (g) 


\section{P. Okoli and others}

Table 2. ANOVA Table of the weight $(\mathrm{g})$ of common buzzards

\begin{tabular}{llllll}
\hline Source & $\begin{array}{l}\text { Type III Sum of } \\
\text { Squares }\end{array}$ & df & Mean Square & F & Sig. \\
\hline Corrected & $1612598.018^{\mathrm{a}}$ & 29 & 55606.828 & 48.006 & 0.000 \\
Model & 77289115.042 & 1 & 77289115.042 & 66724.526 & 0.000 \\
Intercept & 94080.164 & 5 & 18816.033 & 16.244 & 0.000 \\
Weight & 1518517.853 & 24 & 63271.577 & 54.623 & 0.000 \\
Buzzards & 138999.771 & 120 & 1158.331 & & \\
Error & 79040712.830 & 150 & & & \\
Total & 1751597.788 & 149 & & & \\
Corrected Total & 140 & & & \\
\hline
\end{tabular}

a. $\quad$ R Squared $=.921$ (Adjusted R Squared $=0.901)$

There is significant difference between the weights $(\mathrm{g})$ at 0.05 level of significance

Table 3. Duncan multiple range test table

\begin{tabular}{l|l|l|l|l}
\hline Weight & N & Subsets & 2 & 3 \\
\cline { 3 - 5 } & & 1 & & \\
\hline weight1 & 25 & 669.5720 & 701.4520 & \\
\cline { 3 - 5 } weight2 & 25 & & & 726.3520 \\
weight3 & 25 & & & 730.9720 \\
weight4 & 25 & & & 738.5920 \\
weight5 & 25 & & & 0.203 \\
weight6 & 25 & & 1.000 & \\
Sig. & & 1.000 & & \\
\hline
\end{tabular}

Means for groups in homogeneous subsets are displayed based on observed means.

The error term is Mean Square (Error) $=1158.331$.

a. Uses Harmonic Mean Sample Size $=25.000$.

b.Alpha $=0.05$. From the Duncan multiple range test weight 1 and weight 2 are significantly different from every other weight at 0.05 level of significance.

Table 4. Regression model coefficients

\begin{tabular}{lllllll}
\hline Model & & \multicolumn{2}{l}{ Unstandardized Coefficients } & $\begin{array}{l}\text { Standardized } \\
\text { Coefficients }\end{array}$ & $\mathrm{t}$ & Sig. \\
\cline { 3 - 6 } & & $\mathrm{B}$ & Std. Error & Beta & & \\
\multirow{2}{*}{1} & (Constant) & 0.942 & 73.078 & & 0.013 & 0.990 \\
& H20 & 1.795 & 2.297 & 0.161 & 0.781 & 0.443 \\
\hline
\end{tabular}

Dependent Variable: weight gain/lost

Regression model: Weight gain/lost $=0.942+1.795 \mathrm{H}_{20}$ i.e. a unit increase in the average quantity of water will result in corresponding increase of 1.795 weight gain in common buzzards.

The computation from the control shows that the average quantity of water lost to the atmosphere daily during the study period was $10.7 \mathrm{cc}$.

The study indicated clearly that the birds require additional water supply apart from what they get from their meat meals. This was proven by the fact that all the studied buzzards took some quantity of water every day of the study even after correcting for the water lost to the atmosphere through evaporation. This was particularly so while they were in captivity without access to whole live animal preys, which obviously would supply them with more water than frozen pre-slaughtered meat rations. There is no doubt that disease conditions may cause reduced food consumption by captive birds, but sick birds are known to take more water (Wobeser, 2002). A falconet was reported dead due to impaction of the gizzard and subsequent obstruction of the intestinal tract (Hamerton, 1998; Cooper, 2002; Gombobaatar et al., 2004) such condition was very unlikely if the moisture 
content of the diet were adequate (Cooper, 1988). Deprivation of water has been incriminated as the cause of visceral gout in reptiles which is also possible in birds (Cooper, 1988). After taking cognizance of invisible water lost to the atmosphere through evaporation, an average buzzard of $723,9 \mathrm{~g}$ from the studied sample population consumed averagely $31.4 \mathrm{cc}$ of water per day which is $4.3 \%$ of its live body weight. The analysis of water consumed against weight gained by the buzzards for the first 10days and another 15days gave regression coefficients of 0.332 and 0.302 respectively. The difference in the coefficient could be as a result of the buzzard adjustment to their new environment, recovery from ailments, effects of the medicaments and stress of handling and captivity. The allometric equation to estimate the daily water consumption of birds generally as updated in 2011 (Bird and Ho, 1976; Woberser, 2002) is; bird drinking rate $=0.059 \mathrm{x}$ (w) 0.67 . Where $\mathrm{w}$ is the weight of the birds. Using the above equation a common buzzard of $724.9 \mathrm{~g}$ will consume $0.059 \times 724.9 \times 0.67=28.7 \mathrm{cc}$ of water per day. This compares very closely with the figure $31.4 \mathrm{cc}$ obtained from this investigation which is barely 9.4\% more than the estimate obtained using the allometric equation for water consumption in birds.

Captive common buzzards do not only need additional drinking water, they need it ad libitum because of the enormous role water plays in raptor diet and health (Aguirre, 2009). Captive common buzzards may abstain from food for a whole day but would not abstain from drinking water. There is significant difference between the weights of the buzzards at 0.05 level of significance. Duncan multiple range test shows that $\mathrm{W}_{1}$ and $\mathrm{W}_{2}$ are significantly different from every other weight at 0.05 level of significance.

Captive common buzzards should be provided with clean drinking water ad libitum as long as they are not fed with whole live preys as in free wild living. The water will augment what they get from their pre-slaughtered meat meals, reduce the stress of confinement and help them in recovery from diseases, bio-metabolism of drugs, excretion, homeostasis and digestion. The average daily water consumption of studied common buzzards was equivalent of $4.3 \%$ of their live body weight after correcting for the water lost to the atmosphere through evaporation. This implies that captive common buzzards should be served water equivalent to $15 \%$ of their live body weight so that even after loss by evaporation, they will still have enough water to drink, From this investigation the average water lost by evaporation daily $(10.7 \mathrm{cc})$ and that consumed by each buzzard daily $(31.4 \mathrm{cc})$ add up to $5.8 \%$ equivalent of the live body weight of the studied captive common buzzard which was $724.9 \mathrm{~g}$. This value is in agreement with the $10 \%$ live body weight of water suggested by Patrick (1993) for raptors.

\section{ACKNOWLEDGEMENTS}

The authors appreciate the contribution of A. Legakis of the University of Athens in the supervision of the work and Philips Dragoumis from the Hellenic Wildlife Hospital, Aegina, Greece who helped in the safe keeping and handling of the common buzzards.

\section{REFERENCES}

1. Aguirre AA (2009). Essential veterinary education in zoological and wildlife medicine: a global perspective. Scientific and Technical Review of the Office International des Epizooties 28: 605-610.

2. Amadon D and Bull J (1988). Hawks and owls of the world: a distributional and taxonomic list, with the genus Otusby Marshall JT and King BF Proc. West. Found. Vertebrate Zoology 3: 294-357.

3. Animal Nutrition Publications (2003). Texas A \& M University, Department of Animal Science 33 Kleberg/2471 Tamu/college Station Texas 77843-2471.

4. Anonymous (2015). Landscaping for wildlife. www.extension.psu.edu Accessed on $22^{\text {nd }}$ October, 2015, 12:52pm.

5. Arroyo BJ, Garcia JT and Retagnolle VB (2004). Circus pygargus Montagu's Harrier. Update 6: 39-53.

6. Bird DM and Ho SK (1976). Nutritive values of whole-animal diets for captive birds of prey. Raptor Research 10: 45-49.

7. Burrow N and Demey RD (2001). A guide to the birds of Western Africa. Princeton University Press, Princeton, NJ. U.S.A.

8. Cooper JE (2002). Birds of prey: health and disease, 3rd Ed. Black well Science, Oxford, United Kingdom.

9. Cooper JE (1988). Veterinary Aspects of Captive Birds of Prey pg 166, Published by the Standfast press, the Old Rectory, Cherington, Tetbury, Gloucestershire.

10. Gombobaatar S, Sumiya D, Shagarsuren O, Potapov E and Fox NE (2004). Saker Falcon (Falco cherrug milvipes Jerdon) mortality in central Mongolia and population threats. Mongolian Journal of Biological Science 2: 13-22. 


\section{P. Okoli and others}

11. Hamerton AE (1998). Report in the Deaths Occurring in society Gardens During 1937, Proceedings of the Zoological Society of London 105: 489-526.

12. Patrick TR (1993). Medical Management of Birds of Prey Pg 64, Published Raptor Centre, University of Minnesota.

13. Paul D (2003). Wildlife disease surveillance by the veterinary laboratory agency. Microbiology Today 30: 151-159.

14. Resource Document (1996). Update 17 Sept 2001. Water Management and Resources Division Ministry of Environment, Land and Parks, North America.

15. Wobeser G (2002). Disease Management Strategies for Wildlife. Scientific and Technical Review of the Office International des Epizooties 21: 159-178. 